\title{
Implementasi Reforma Agraria pada Masa Orde Lama dan Reformasi
}

\author{
Vindria Shafa Clarissha1, Recca Ayu Hapsari², Nada Alia Husna ${ }^{3}$, M. Argo Renaldo ${ }^{4}$ \\ ${ }_{1,2,3,4}$ Fakultas Hukum, Universitas Bandar Lampung \\ J1. ZA Pagar Alam No 26, Kedaton, Labuhan Ratu, Bandar Lampung, Indonesia \\ Correspondence email: vixidria.18211242@student.ubl.ac.id, recca@ubl.ac.id
}

\begin{abstract}
Abstrak. Landreform merupakan metode untuk memecahkan permasalahan agraria agar ketimpangan ekonomi pendapatan penduduk di indonesia. serta timpangan dan penguasa dan pemilik tanah dapat terselesaikan dengan baik agar kemajuan ekonomi bangsa dapat merata dan kesejahteraan dapat tercapai. Kebijakan yang diambil oleh pemimpin Negara harus mengkordinir kepentingan seluruh warga Negara Indonesia tanpa membeda-bedakan golongan ataupun kebijakan nya haruslah sama dengan prinsip peraturan undang-undang yang berlaku. Dan kebjakan landreform pada masa orde lama maupun reformasi tentu merupakan. Suatu cara untuk menciptakan kebijakan yang responsif yang dapat mengkordinir kepentingan. Seluruh warga Negara namun dengan cara yang berbeda-beda yang terpenting dalam menjalankan. Suatu kebijakan tetap harus berlandaskan ketentuan hukum yang berlaku dikarenakan Indonesia Negara hukum berdasarkan UUD 1945, dalam membuat konsep kebijakan agraria agar dapat berjalan dengan. semestinya melibatkan ilmuan, pejabat, aktivis dan Juga elemen masyarakat.
\end{abstract}

Kata Kunci: Implementasi, Reforma Agraria, Masa Orde Lama, Reformasi

Abstract. Reform is a method to solve agrarian problem for economic inequality of population income in Indonesia. and the food and ruler and landlord are well resolved so that the economic progress of the nation can be evenly and well-being achieved. The policy taken by the state leaders must comply with the interests of all Indonesian citizens without discriminate or their policies should be the same as the principles of applicable law. And the reform of the reforms in the old order and the Reformation is certainly. A way to create a responsive policy that can coordinate interest. All citizens but in different ways are most important in running. A policy remains to be based on the provisions of the law due to Indonesia state law under the UUD 1945, in making the concept of agrarian policy in order to walk with. Should involve scientists, officers, activists, and also elements of society.

Keywords: implementation, agrarian reform, old order period, Reformation

\section{PENDAHULUAN}

Indonesia negara agraris. Agraris artinya masyaratnya harus memiliki tanah. Karena sebagian besar rakyat NKRI kehidupan bergantung pada tanah, seperti pertanian. Masalah tanah,masalah klasik pada penguasa tanah yang terjadi di masyarakat agraris. Landreform adalah cara pemecah masalahnya. Karena landreform bisa memecahkan masalah agraria. Landreform asal kata dari bahasa Inggris "land" dan "reform". Land " tanah" dan Reform "perombakan atau perubahan struktur pertanian baru". Landreform dalam arti sempit yaitu penataan ulang struktur penguasa dan pemilik tanah, konsep reform agraria bagian pokoknya.

Dan perkembangan masa ke masa konflik agraria terus menjadi tontonan pilu yang tidak kunjung berlalu . Solusi beru pa reforms agraria tidak kunjung direalisasikan kendati telah dibentuk peraturan yang menegaskan urgensi dari reforms agraria tersebut. Keberhasilan negara lain mestinya mampu membuat kita berkaca dan memahami penyelesaian momok di negeri ini. secara historis, UUPA merupakan aturan pertama terlengkap yang sebelumnya telah didahului beberapa pengaturan land tenure soal pengalihan hak kebendaan dari Belanda/Eroupa. Undang-undang ini disesuaikan dengan kondisi Indonesia yang sekaligus pengambil alihan tanahtanah di bawah penguasaan Belanda.

Diskriminasi kepemilikan tanah di Indonesia masih belum dapat diselesaikan oleh pemerintahan yang berkuasa hingga saat ini. Solusi berupa reformasi agraria terns digaungkan oleh pihak-pihak yang peduli dengan permasal ahan agraria. Reforms agraria adalah upaya restrukturisasi kepemilikan, penggunaan, dan pemanfaatan tanah yang tiinpang melalui legislasi dan program yang terencana deini keadilan dan kesejahteraan masyarakat.

Reforms agraria bagi sejarah Indonesia inungkin merupakan utopia yang pernah dibawakan Soekarno. dibuat legislasi yang mengatur tentang pemilikan tanah saat itu, Undang- Undang Pokok Agraria (HUPA) 1960 menjadi pegangan angan kesejahteraan masyarakat kita. Meski masih berlaku, keberlanjutan reforma agraria di Indonesia tenggelam dalam agenda besar lain. Setelah semangat reforms agraria di masa Soekarno memudar, siapapun yang berkapasitas untuk menuntas ketimpangan tanah seakan tutup mata dengan masalah dan manfaat keberhasilan reforms agraria serta betapa hal ini merupakan kunci kemakmuran ekonomi.

Landreform terdapat konsep pembangunan yang telah terencana, konsep ini sudah di yakini Negaranegara di dunia khususnya negara berkembang. Konsep Landreform sejak tahun 1960Sudah ada di penjuru dunia. 
PBB juga telah memberi perhatian saat melakukan Landreform itu. Bank Dunia juga lebih focus memperhatikan pelaksanaan Landreform. Bank Dunia juga memberi panduan penting pada negara dalam pelaksanaan Landreform. $^{1}$

Tapi tujuan itu dilupakan banyak sekali petani yang berpikiran tanah yang mereka garap bukan milik sendiri dan para petani itu banyak yang tidak merasakan kemakmuran di indonesia ini. Indonesia ini pada dasarnya Negara agraris yang punya lahan luas, subur, yang seharusnya untuk para petani di indonesia tapi pada nyatanya tidak sangat miris bukan.

Dalam segi bidang ekonomi pada penduduk di Indonesia terdapat kesenjangan antara pemilik dan penguasa tanah yang menonjol dan ironis. Ada dua sisi permasalahan kesenjangan ini. Satu sisi banyak orang kaya yang memiliki banyak tanah yang dijadikan aset dan investasi, dan dilain sisi petani hanya mampu memiliki satu bidang tanah yang bias dimanfaatkan sebagai cara memenuhi biaya hidup keluarganya serta ada juga yang tidak punya tanah garap.Berdasarkan pembahasan di atas kita bahas dalam tulisan ini terkait penerapan land reform dari masa orde lama dan masa reformasi sebagai perbandingan penerapan land reform pada masa sekarang dengan masa awal mula UUPA dibentuk.

Dalam rangka menyukseskan reform agraria itu perlu adanya ilmu pengetahuan yang mumpuni (dari para ilmuawan, pejabat, dan aktivis) dan juga kesadaran serta dukungan dari masyarakat. UUPA pada pelaksanaannya sudah bnyak sekali kekurangannya karena usianya sudah lebih dari 50 tahun. Hingga saat ini UUPA belum secara maksimal diimplementasikan dalam menyelesaikan permasalahan terkhusus terkait dualism hukum tentang pengaturan agrarian di Indonesia. Belum maksimalnya perencana penggunaan tanah akibatnya praktek di pihak asing menguasai dan memiliki tanah sehinnga perlu kita lihat dalam penerapan reforma agraria di Indonesia sudah berjalan dengan semestinya atau belum ${ }^{2}$. Berdasarkan latarbelakang diatas perrnasalahan yang kami angkat adalah Bagaimana Implementasi Landreform Pada Masa OrdeLama? Bagaimana Implementasi Landreform Pada Reformasi? Bagaimana Perbandingan Dampak peru bahan dari Land Reform pada masa Orde Lama dan Reformasi?

\section{HASIL DAN PEMBAHASAN \\ Implementasi Land Reform Pada Masa Orde Lama}

Pada masa Orde Lama adanya perencanaan peraturan tentang Agraria Nasional disusun pada periode antara tahun 1945-1959. Dalam perencanaan dilakukan penyesuaian dengan konstitusi dan konfigurasi politik masa orde lama. Adapun penyesuaian tersebut adalah Undang-Undang No 5 tahun 1960. Sebagai tuntutan masa orde lama, implementasi UUPA harus dapat merubah sistem yang dianut dalam Agrariche Wet (AW) 1870. Maka hukum adat saat itu digunakan sebagai landasan pembangunan serta induk dari program Landreform Indonesia, dengan tujuan untuk menghapuskan sistem feodalisme dan melaksanakan hak konversi dalam hukum tanah.

Dari segi sejarah orde Lama, adanya implementasi Landreform pada saat itu sebagai kebijakan yang revolusioner pada masa pembangunan orde lama, sebab dikeluarkannya peraturan tentang redistribusi tanah sebagai amanat isi dari UUPA. Karena UUPA mengamanatkan bahwa hal yang menjadi syarat pembangunan tata perekonomian adalah dengan membebaskan sebanyak-banyaknya lahan para petani dan rakyat.

Tujuan dari Landrreform ini adalah menghilangkan segala pengaruh kolonialisrne, imperialisrne, feodalisme dan kapitalisrne, dengan cara melaksanakan dasar-dasar pada industrilisasi. Baik itu industri dasar dan industri berat yang dikuasi oleh negara. Berdasarkan TAP MPR Rl Nomor11/MPRS/1960 serta dala Manifesto Politik, menjelasakan adanya tiga landasan filosofis pembangunan yaitu: anti penghisapan atas manusia oleh manusia, kemandirian ekonomi; dan anti kolonialisrne, imperialisrne, feodalisme dan kapitalisrne dengan landreform sebagai agenda pokoknya.'

Pada periode 1960-1966 seluruh peraturan hukum di bidang tanah harus merujuk pada undang-undang agraria yang menjadi pokok sidang yang diprioritaskan. Landreform yang dimplementasikan memiliki prinsip bahwa tanah adalah alat produksi bukan alat penghisapan, yang dalam hal ini disebut sebagai pembangunan semesta.

Pelaksanaan landreform pada masa orde lama diberlakukan dengan dikeluarkan perpu nomor 56 tahun 1960 tentang penetapan luas tanah pertanian. adapun isi dari perpu nomor 56 tahun 1960 tenang pendistribusian tanah pada masyarakat petani yang tidak mempunyai tanah dengan memberikan tanah pertanian sebesar 2 hektar. namun pada kenyataannya pelaksanaan landreform pada masa orde lama mengalami kegagalan dengan beberapa sebab diantaranya adanya krisis penguasaan sumber-sumber agraria.

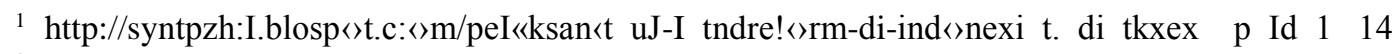

2 Yanis Maladi. 2013.Reforma Agraria Berparadigma pancasila dalam penataan kembali Politik Agraria NAsional. Mimbar Hukum. Volume 25 Nomor 01 hlm 28 
Periode Orde Lama, hukum pertanahan didorong untuk lebih diutamakam untuk tercipta keadilan koinutatif diberi fasilitas dan kemuhan menguasai/memiliki tanah kepada kelompomk mayoritas yang lemah, contoh petani tidak ada tanah atau tanahnya sempit, petani penggarap, petani yang menggarap tanah dikebun serta koperasi sebagai organisasi yang dibentuk oleh kelompok tersebut. "Selain itu agar ada keadilan korektif yaitu dengan memberikan fasilitas dan kemudahan kepada kelompok mayoritas yang pada periode sebelumnnya tidak diurus dalam kebijakan pertanahan.'

\section{Implementasi Land Reform Pada Masa Reformasi}

Setelah melalui masa orde baru yang panjang yang ditandai dengan perubahan konstelasi politik, gema demokrasi yang semakin kencang dan produk hukum penting pada saat itu adalah keluarnya Tap MPR No X/MPR/2009 tentang politik ekonomi dalam rangka demokrasi ekonomi. Peraturan tersebut menunjukan perbedaan yang mendasar pada kebijakan masa orde baru. Peraturan tersebut dibuat dengan mempertimbangkan Pasal 33 ayat (3) UUD 1945.

Dalam rangka pembangunan ekonomi tersebut negara telah menyusun peraturan-peraturan yang berpihak pada kepentingan umum. Sebagai contoh program landreform tersebut dapat masuk pada program pembaruan agrarian, yiatu undang undang tentang pengeloaan SDA, salah satu program unggulan dalam rangka pembaharuan agrarian.

Beberapa peraturan perundang-undangan tentang pengelolaan SDA (agraria) dikeluarkan sejak dilakukan reformasi pemerintahan ditahun 1998. Baik itu yang dinilai merupakan langkah rnaju maupun yang justru dinilai mundur dari substansi peraturan- peraturan sebelumnya. Landrefrm kembali masuk dalam program penting pembaruan agraria, yaitu disebut dalam Pasal 5 Tap MPRRINo.1X/MPR/2001 salah satu kebijakan melakukan pembaruan agrarian yaitu

Penataan ulang penguasaan, pemilikan, pengunaan dan manfaat tanah (landreforin) yang berkeadilan dengan memperhati kan kepemilikan tanah oleh rakyat pendataan tentang tanah melalui investarisasi dan registrant penguasaan, pemilikan, penggunaan dan pemanfaatan tanah secara komprehensif dan sistem untuk pelaksanaan landreform. Dan dalam Pasal 6 Tap MPR Rl No.IX/MPR/2001, juga ada beberapa hal yang menjadi pelaksanaan pembaruan agraria adalah:

1. Mengkaijian ulang di berbagai peraturan undang-undang

2. Menata kembali penguasaan, pernilikan, penggunaan dan pemanfaatan tanah(landreform)

3. Menghadirkan kembali data-data pertanahan

4. Menyelesaikan konflik-konflik

5. diperkuat kelembagaan,dan

6. diupayakan biaya

Dalam perubahan tatanan struktur adrninistrasi birokrasi,menjadi kewenangan untuk membuat dengan berlakunya otonomi daerah. Adapun kewangan daerah adalah Otonomi daerah saat ini, secara "lokal" ada peluang untuk melakukan reform agraria. Saat dilaksanakannya reformasi dan otonomi daerah, perselisihan hanya sebatas masalah tarik ulur adrninistrasi pertanahan. Perencanaan Landreform tidak mendapatkan perhatian yang utama bagi instansi pemerintah, meski masyarakat serta beberapa organisasi petani telah menyuarakan demonstrasi menuntut implementasi reform agraria.

Selanjutnya masa pemerintah Susilo Bambang Yudhoyono, dinilai tidak berhasil. Hal tersebut disebabkan karena masa itu landreform hanya mengandalkan kerja badan pertanahan nasional saja. Sedangkan implementasinya menitikberatkan pada jadwal redistribusi tanah kembali. Bedasarkan catatan Kompas, dibagi 8,15juta hektar lahan ini akan dilakukan pemerintah tahun 2007-2014. Perkiraan, 6juta hektar lahan akan dibagikan pada masyarakat miskin, sisanya 2,15 juta hektar dibagi kepada para pengusaha untuk usaha produktif yang melibatkan petani kebunan. Tanah yang dibagian ini tersebar di Indonesia, lebih diprioritas dipulau Jawa, Sumatera, dan Sulawesi Selatan.

Serta Kementrian Kehutanan dan pertanian, sebagai penyebab gagalnya landreform adalah ketidaksetujuannya usulan BPN untuk menjadi Lembaga pengelola reforma agragia, yakni suatu badan otoritas khusus yang mengurus semua hal-hal yang berkaitan dengan bekas swaraja. Selain menjadwal redistribusi tanah, pada Pemerintahan Susilo Bambang Yudhoyono juga dilaksanakan program sebagai berikut:

1. Perbaiki ketimpangan kepemilikan tanah

2. Meminimalisisr kesenjangan pengangguran dan kemiskinan

3. Dan mengurangi konflik masalah tanah

Namun pada era masa reformasi saat ini, banyak terjadi pekembangan dalam pengaturan hukum agrarian di Indonesia. Adanya perencanaan landreform oleh pemerintah memiliki permasalahan yang segera ditentukan bagaimana landreform dan agrarian reform (pembaruan agrarian) tersebut sebaiknya untuk kondisi di 
Indonesia.serta belum jelas nya pemahaman tentang peran pemerintah dan daerah. Pada era reformasi sampai saat ini persoalan hak kepemilikan tanah yang merupana symbol kesatuan bangsa dan negara. Ada empat masalah pokok agrarian di Indonesia yang telah ditetapkan dalam Tap MPR No. 1X Tahun 2001, yaitu: pemilikan tanah yang sempit dan timpang, konflik pertanahan, inkosistensi hukum, serta kerusakan SDA. Seharusnya menjadi agenda yang pokok untuk diselesaikan sebelum sampai pada rumusan konsep landreform yang ideal yaitu ' land to tiller"”.

\section{Perbandingan Dampak perubahan dari Land Reform pada masa Orde Lama dan Reformasi}

Kebijakan dari pada landreform ditentukan oleh rezim yang memimpin apakah kebijakan itu dapat mengakomodir setiap kepentingan rakyat terkhususnya petani kecil. Salah satu faktor kemajuan suatu bangsa juga dilihat dari kemajuan kesetaraan dan kesejahteraan dibidang agraria apakah kebijakan yang diambil dapat mensejahterakan rakyat atau tidak.

Jika kita lihat dari dampak perubahan antara perbandingan penerapan konsep landreform pada masa orde lama atau pun reformaasi ditentukan pula pada kebijakan yang diambil oleh rezim yang berkuasa. Pada masa orde lama slam hal kebijakan penerapan landreform nya berfokus pada tahap awal pendaftaran tanah untuk tahu dan diberi kepastian pada hukum tentang pemilikan dan penguasaan tanah. Tanah-tanah ini diberi penentuan berlebih (lebihi batas maksimum pemilikan) terus akan dibagi kepetani petani yang tidak ada tanah. Undang-Undang Nomor 2 Tahun 1960 tentang Perjanjian Bagi Hasil. Dan produk hukum pertanahan didorong buat lebih diutamakan agar tercipta keadilan komutatif yaitu dengan diberi fasilitas dan mudah mnenguasai/memiliki tanah pada kelompok mayoritas yang lemah, ada petani tidak ada tanah atau bertanah sempit, petani penggarap, petani yang menggarap tanah dikebunan dan koperasi.

Pada masa reformasi inkonsisten kebijakan terjadi dimana dalam masa reformasi ini banyak berganti rezim yang meinimpin inulai dari Abdurrahinan Wahid, Susilo Bambang Yudhoyono hingga Joko Widodo mempunyai program yang berbeda beda bapak presiden Abdurrahman wahid dengan kebijakan nya terkait distribusi tanah sebagainyak 40 persen dari tanah-tanah perkebunan

Kebijakan bapak presiden susilo bambang yudhoyono dikebijakannya landreform dilakukan dan ditetapkan pada jadwal redistribusi tanah lagi. Dengan catatan Kompas, tanah dibagi 8,15 juta hektar lahan ini akan dilakukan pemerintah tahun 2007 hingga 2014. Diperkirakan, 6 juta hektar lahan itu dibagi buat rakyat miskin, sisanya 2,15 juta hektar sisanya untuk para pengusaha untuk usaha produktif dikebun yang didalamnya ada para petani. Tanah ini banyak tersebar di Indonesia, yang paling banyak di pulau Jawa, Sumatera, dan Sulawesi Selatan.

Kemudian dibawah kepemimpinan bapak presiden joko widodo menjalankan program nasional dengan cara membagi-bagikan sertifikat tanah kepada masyarakat untuk mengelolah tersebut baik dibidang pertanian ataupun untuk perkebunan dan lain sebagainya. Kementerian Agraria dan Tata Ruang di pemerintah Indonesia sudah melahirkan Peraturan Menteri ATR No. 1S Tahun 2016., pada Pasal 3 yaitu penetapan pembatasan kepemilikan tanah pertanian buat perorangan, seperti 20 hektar maksimum pemerintah. Penetapan ini diperkuat lagi adanya kewajiban untuk tanah hanya dapat dialihkan pada pihak lain yang domisili didalam 1 kecamatan letak tanah.'

Dan jika lihat dainpak peru bahan dari landreform pada kedua masa tersebut cukup berbeda dan cenderung menuju kearah yang lebih baik dikarenakan situasi konstelasi politik juga mendu kung dalam inenjalankan program-program reforma agrarian dan tentu sukses tidaknya program kebijakan ditentukan oleh semua pihak.

Dalam implementasi, pengaturan land tenurial di UUPA tidak berjalan dengan baik. Secara konseptual masih ideal sebab pada umumnya sampai saat ini masih diakui sebagai undang-undang yang semangat dan jiwanya sesuai dengan tuntutan masyarakat, yakni mengedepankan kepentingan sebagian besar dari mereka yang kurang beruntung, sebagian besar buruh dan petani, dalam proses pembangunan bangsa ${ }^{4}$. Sebagai turunan banyak peraturan perundang-undangan yang mengatur persoalan land tenurial yang menyimpang dari

UUPA. Seiring dengan berubahnya pembangunan politik ekonomi dari sifatnya yang menekankan pemerataan (sosialisme) menjadi pertumbuhan (kapitalisme) maka UUPA kehilangan legitimasi sosial ekonominya dan tinggallah legitimasi hukumnya ${ }^{5}$.

\footnotetext{
${ }^{3}$ Op cit

${ }^{4}$ Linda Yanti Sulistiawati dan Muhammad Adib Zain, Tanah Dan Hukum Adat Di Indonesia Timur, Jurnal Landreform "membangun kekuatan politik agraria" Volume II/ Desember 2014, hlm 29

5 Achmad Sodiki, Urgensi Peneguhan UUPA dan Peraturan Pelaksanaannya untuk mendukung pelaksanaan pembaruan agraria, dalam Pembentukan Kebijakan Reforma Agraria 2006-2007 : Bunga Rampai Perdebatan. STPN Press, Yogyakarta. Hlm 144
} 


\section{SIMPULAN}

Berdasarkan yang sudah dibahas diatas dapat disimpulkan landreform merupakan sebuah metode untuk memecahkan permasalahan agraria agar ketimpangan ekonomi pendapatan penduduk di Indonesia dan tinmpangnya pemilikan dan penguasa dapat terselasaikan dengan baik agar kemajuan ekonomi bangsa dapat merata dan kesejahteraan dapattercapai.

Dalam kebijakan yang diambil oleh pimpinan Negara harus lah dapat rnengakomodir kepentingan seluruhw Negara Indonesia tanpa membeda- bedakan golongan atau pun kebijakannya harus sama dengan prinsip peraturan undang-undang yang ada.

Dan kebijakan landreform pada masa orde laina maupun reformasi tentu merupakan suatu cara untuk menciptakan kebijakan yang responsive yang dapat inengakomodir kepentingan seluruh warga Negara namun dengan cara yang berbeda-beda yang terpenting dalam menjalankan suatu kebijakan tetap harus berlandaskan ketentuan hukum yang berlaku dikarenakan Indonesia Negara hukum berdasarkan UUD RI 1945.

\section{DAFTAR PUSTAKA}

Achmad Sodiki, Urgensi Peneguhan UUPA dan Peraturan Pelaksanaannya untuk mendukung pelaksanaan pembaruan agraria, dalam Pembentukan Kebijakan Reforma Agraria 2006-2007 : Bunga Rampai Perdebatan. STPN Press, Yogyakarta

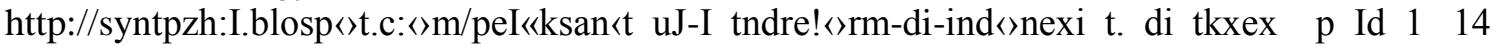

Yanis Maladi. 2013.Reforma Agraria Berparadigma pancasila dalam penataan kembali Politik Agraria NAsional. Mimbar Hukum. Volume 25 Nomor 01

Linda Yanti Sulistiawati dan Muhammad Adib Zain, Tanah Dan Hukum Adat Di Indonesia Timur, Jurnal Landreform "membangun kekuatan politik agraria" Volume II/ Desember 2014 